\title{
Chronic kidney disease referrals from general practitioners pre- and post National Institute for Health and Care Excellence guidance 2014
}

\author{
Authors: Aruna Arjunan, ${ }^{A}$ Mohammad Saddam Jeelani, ${ }^{B}$ Sharon Docherty ${ }^{C}$ and Jo Taylor ${ }^{D}$
}

\section{Introduction}

Mortality from chronic kidney disease (CKD) is increasing. Most patients die from cardiovascular disease and management of cardiovascular risks is key to prevent both mortality and progression to end-stage renal disease. In 2014, the National Institute of Health and Care Excellence (NICE) introduced guidance to help general practitioners (GPs) manage CKD patients.

Aim

We aimed to determine the impact of the updated CKD guidance on CKD/cardiovascular risks optimisation and the timeliness of referral from the primary care.

Methods

All new GP referrals to the Regional Renal Service in 2012 and 2016 were analysed. Data were collected on patient age, estimated glomerular filtration rate (eGFR) at referral, blood pressure (BP), smoking, body mass index, glycated haemoglobin (HbA1c; in diabetic patients) and lipid assessment.

Results

A total of 486 new GP referrals were received in 2012, and 574 in 2016 ( $18 \%$ increase post NICE CKD guideline). Post NICE, fewer stage 4 and 5 CKD patients were being referred. But late referrals (eGFR $<20 \mathrm{~mL} / \mathrm{min} / 1.73 \mathrm{~m}^{2}$ ) were not improved. BP control had improved. More patients had cholesterol-levels checked. The number of smokers and obese patients had not improved.

\section{Conclusion}

Post NICE guidelines, GPs are better in optimising BP. Diabetes management and lifestyle modifications need further improvement.

KEYWORDS: Chronic kidney disease, NICE guidelines

Authors: ${ }^{\text {A }}$ specialty registrar, Dorset County Hospital, Dorchester, UK; ${ }^{B}$ core medical trainee, Dorset County Hospital, Dorchester, UK; ' senior lecturer (academic) in quantitative methodology and statistics, Bournemouth University, Bournemouth, UK; ${ }^{\text {D }}$ consultant nephrologist, Dorset County Hospital, Dorchester, UK

\section{Introduction}

Mortality from chronic kidney disease (CKD) is increasing worldwide and is currently ranked 14 th commonest cause of death. ${ }^{1}$ Management of cardiovascular risk in CKD patients is the key to prevent both death and decline of renal function to the point of end-stage renal disease (ESRD). In the UK, $14 \%$ of men and $13 \%$ women have CKD, the majority being managed in primary care. In 2014, the National Institute for Health and Care Excellence (NICE) introduced guidance to help general practitioners (GPs) manage patients with CKD, focusing on cardiovascular risk and prevention of late referral of patients likely to require renal replacement therapy. ${ }^{2}$

The study was aimed at determining the impact of the updated CKD guidance on CKD/cardiovascular risk optimisation and the timeliness of CKD referrals from the primary care.

\section{Methods}

All new GP referrals to the Regional Renal Service in 2012 and again in 2016, 2 years after the introduction of NICE CKD guidance in 2014, were analysed. Data were collected on patient age, CKD stage and estimated glomerular filtration rate (eGFR) at referral, renal imaging pre-referral, blood pressure (BP), smoking, body mass index (BMI), glycated haemoglobin ( $\mathrm{HbA} 1 \mathrm{c}$; in diabetic patients) and lipid assessment.

\section{Results}

A total of 486 new GP referrals were received in 2012, compared with 574 in 2016. Data completion was 100\% for renal imaging pre-referral, BP, BMI, diabetic status and lipid assessment at referral. Nearly one-third of referrals in 2012 (29.01\%) and one-quarter in 2016 (24.39\%) were aged $>80$ years (see Fig 1). The distribution of eGFR of the referred patients is shown in Fig 2. Two patients in both cohorts did not have eGFR/renal stage assessments due to age ( $<18$ years), and one patient in the 2016 cohort refused blood testing.

In $2012,27.8 \%$ and in $2016,30.7 \%$ of referrals were diabetic. Of the patients with diabetes, $60 / 134(44.8 \%)$ in 2012 , and $82 / 176$ $(46.6 \%)$ in 2016 had $\mathrm{HbA} 1 \mathrm{c}$ of greater than $58 \mathrm{mmol} / \mathrm{mol}$. With $11 / 134(8.2 \%)$ of diabetic patients in 2012 , and $13 / 176(7.4 \%)$ diabetic patients in 2016 having HbA1c greater than 86 mmol/mol. $\mathrm{HbA1c}$ was not measured in one of the 2012 diabetic patients. 
Fig 1. Distribution of new patients referred to renal clinic from general practitioners based on age before and after the introduction of National Institute of Health and Care Excellence guidelines CG182.

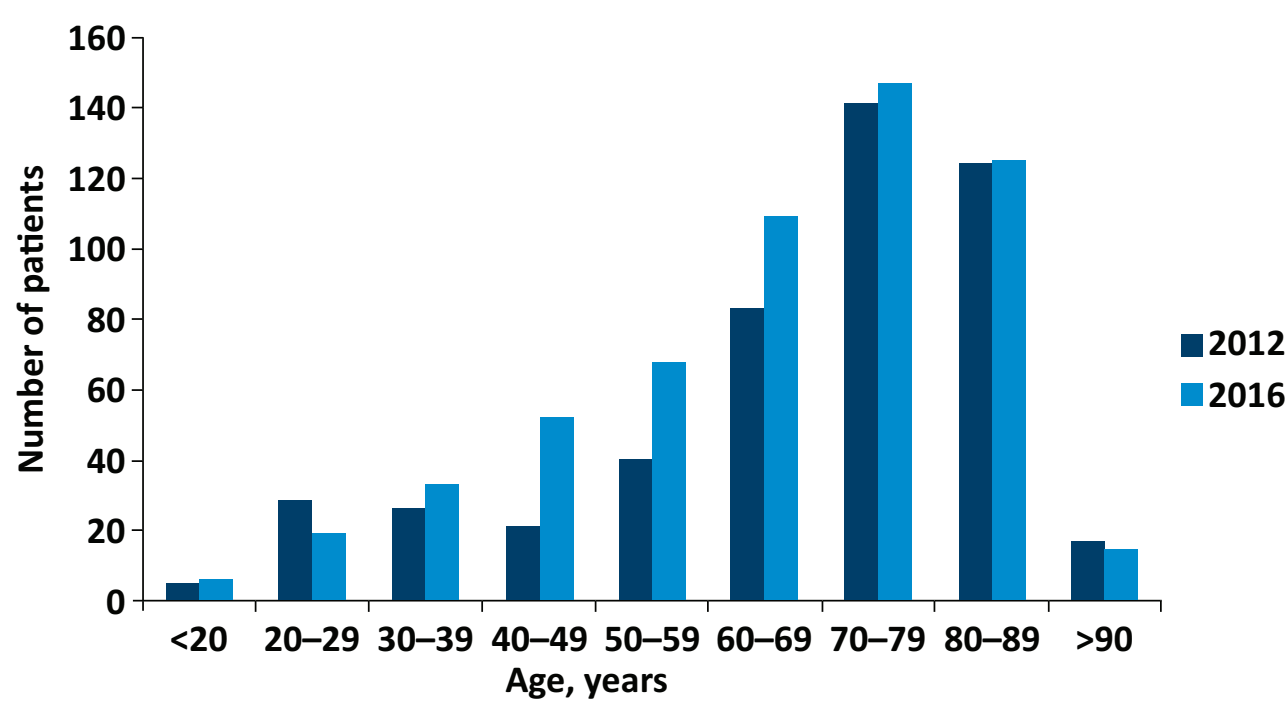

In 2012, 167 patients had a systolic blood pressure (SBP) less than $140 \mathrm{mmHg}$ compared with 245 in 2016. 402/486 (82.7\%) patients referred in 2012 and 509/573 (88.8\%) patients referred in 2016 had cholesterol levels checked. Of those tested, $14.9 \%$ patients in 2012 and $15.9 \%$ in 2016 had a serum total cholesterol of $6.3 \mathrm{mmol} / \mathrm{L}$ or greater.

The proportion of obese patients referred is shown in Fig 3. In 2012, $11.7 \%$ and in $2016,12.6 \%$ of referred patients were current smokers at the time of referral. Pre-referral, renal ultrasound was done only in 206/438 patients in 2012 and 252/529 patients in 2016; renal imaging was not required from 48 in 2012 and 45 in 2016.

The change in the proportion of cardiovascular risk factors post NICE guidelines is shown in Table 1. Post NICE guidelines, there has been an $18 \%$ increase in GP referrals. The number of smokers and obese patients in the referred population have not changed. Comparatively, a lesser proportion of patients had SBP $>140 \mathrm{mmHg}$ and significantly fewer patients had diastolic BP $>90 \mathrm{mmHg}$ post NICE guidance. Significantly more patients have had cholesterol levels checked $(p=0.004)$. Post NICE guidelines, although significantly fewer stage 4 and 5 CKD patients are being referred $(p<0.001)$, there is no statistically significant improvement in late CKD referrals (eGFR $<20 \mathrm{~mL} / \mathrm{min} / 1.73 \mathrm{~m}^{2}$, $p=0.272$ )

\section{Discussion}

CKD is associated with an increased risk of cardiovascular disease and related mortality. ${ }^{3,4}$ Impaired kidney function and raised concentrations of albumin in urine also increase the risk of cardiovascular disease by two to four times and are independent predictors of mortality risk. ${ }^{5,6}$ Stroke risk also increases linearly and additively with declining GFR and increasing albuminuria. ${ }^{7}$

The prevalence of CKD stages 3-5 increases with age, especially in those above 80 years of age. ${ }^{8}$ Among patients of all ages, there is an inverse association between eGFR and the proportion of deaths from a cardiovascular cause. ${ }^{5,7}$ However, among those with comparable levels of eGFR, older patients are more likely to die than reaching ESRD requiring renal replacement therapy. ${ }^{9}$

High BMI is a common, strong, potentially modifiable and independent risk factor for CKD progression and death. ${ }^{10,11}$ A metaanalysis concluded from smaller, short-duration studies in patients
Fig 2. Distribution of referred patients based on estimated glomerular filtration rate at the time of referral before and after the introduction of National Institute of Health and Care Excellence guidelines CG182. eGFR = estimated glomerular filtration rate.

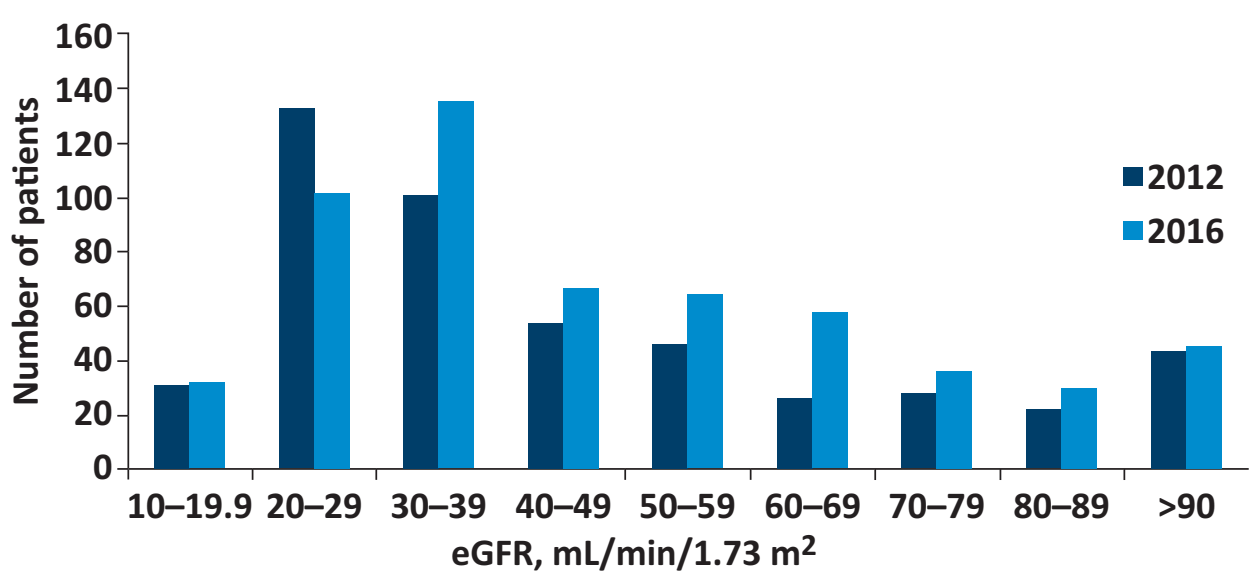




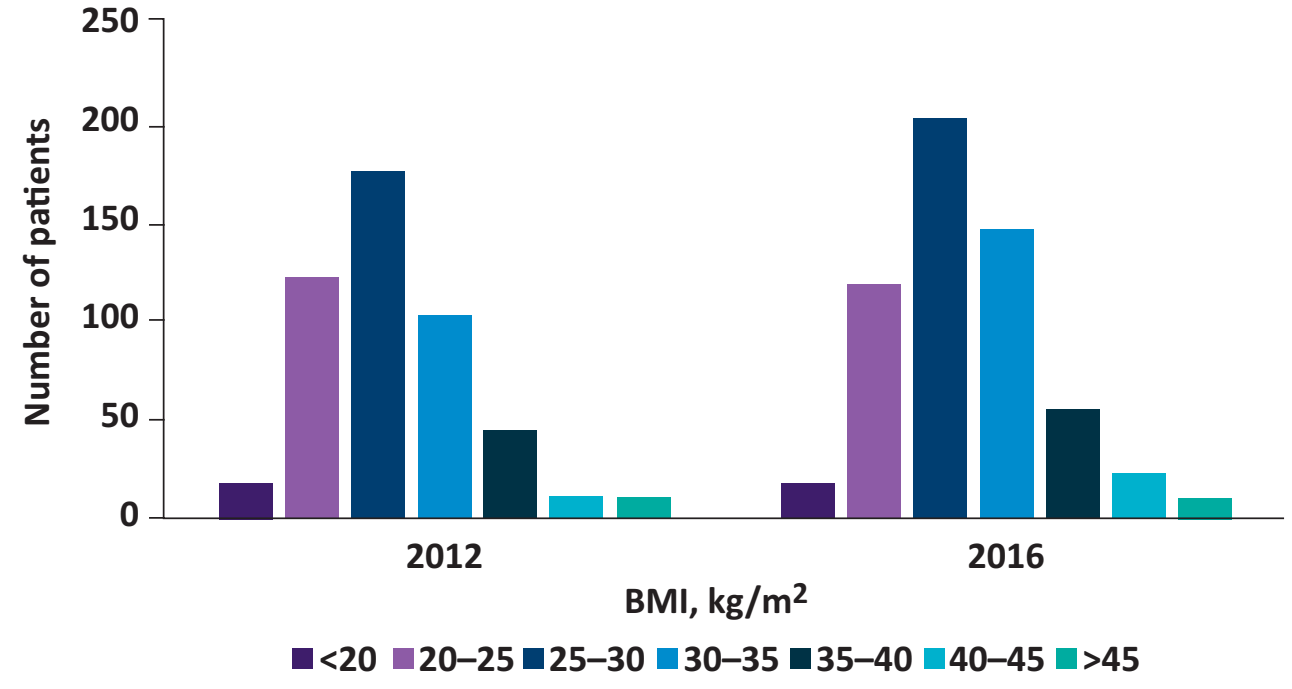

Fig 3. Distribution of patients based on body mass index before and after the introduction of National Institute of Health and Care Excellence guidelines CG182. $\mathrm{BMI}=$ body mass index. with CKD that nonsurgical weight loss interventions reduce proteinuria and $\mathrm{BP}$ and seem to prevent further decline in renal function. ${ }^{12}$

Poorly controlled diabetes is associated with greater risk of microvascular complications in both type 1 and type 2 diabetics. ${ }^{13,14}$ Diabetes is now the most common cause of ESRD in developed countries and diabetic patients are more likely to require dialysis and less likely to be transplanted. ${ }^{15}$

Hypertension is a well-established risk factor for cardiovascular disease (CVD) and a major promoter of CKD progression in both

\begin{tabular}{|c|c|c|c|c|}
\hline $\begin{array}{l}\text { Change in } \\
\text { proportion }\end{array}$ & $\begin{array}{l}\text { Pre-NICE } \\
\text { yes, \% }\end{array}$ & $\begin{array}{l}\text { Post NICE } \\
\text { yes, \% }\end{array}$ & $x^{2}$ & $\mathrm{p}$-value \\
\hline Stage 4 and 5 & 33.9 & 23.5 & 14.024 & $<0.001$ \\
\hline $\begin{array}{l}\text { eGFR } \\
<20 \mathrm{~mL} / \mathrm{min} / \\
1.73 \mathrm{~m}^{2}\end{array}$ & 7.9 & 6.1 & 1.206 & 0.272 \\
\hline $\begin{array}{l}\text { Ultrasound } \\
\text { pre-referral }\end{array}$ & 47.0 & 47.5 & 0.025 & 0.875 \\
\hline $\begin{array}{l}\mathrm{SBP}>140 \\
\mathrm{mmHg}\end{array}$ & 65.6 & 57.4 & 7.483 & 0.006 \\
\hline $\begin{array}{l}\mathrm{DBP}>90 \\
\mathrm{mmHg}\end{array}$ & 26.3 & 19.0 & 8.100 & 0.004 \\
\hline $\begin{array}{l}\text { Cholesterol } \\
\text { tested }\end{array}$ & 82.7 & 88.8 & 8.178 & 0.004 \\
\hline High BMI & 34.8 & 40.8 & 4.102 & 0.043 \\
\hline Diabetic & 27.8 & 30.7 & 1.094 & 0.296 \\
\hline Smoker & 11.7 & 12.6 & 0.172 & 0.678 \\
\hline
\end{tabular}

diabetic and nondiabetic kidney disease. ${ }^{16,17}$ The reduction in BP significantly reduces the risk of death and cardiovascular disease in general population ${ }^{18-21}$ and is markedly reno-protective in CKD population, regardless of the type of drug administered. ${ }^{22-25}$ NICE recommends aiming a systolic $B P$ of less than $140 \mathrm{mmHg}$ in CKD patients and less than $130 \mathrm{mmHg}$ in CKD patients with diabetes and/or proteinuria.

Reduction of low-density lipoprotein, cholesterol, with medications safely reduces the incidence of major atherosclerotic events in patients with less advanced chronic kidney disease. ${ }^{26}$

Risk of death is higher in CKD patients who are current smokers compared with non-smokers and the risk increases with increase in number of daily cigarettes. ${ }^{27}$

\section{Conclusion}

In this single centre audit of new GP referrals to the renal outpatient department, the impact of NICE CKD guidance published in 2014 was better control of BP pre-referral, and increased testing of lipid levels. There was a worrying trend towards increased prevalence of diabetes and increased patient obesity. Managing obesity and smoking as risk factors for the development of renal disease remain challenging for both GPs and renal physicians.

\section{References}

1 Webster AC, Nagler EV, Morton RL et al. Chronic Kidney Disease. Lancet 2017:389:1238-52.

2 National Institute of Health and Care Excellence. Chronic kidney disease in adults: assessment and management. Clinical guideline [CG182]. NICE, 2015. www.nice.org.uk/guidance/CG182.

3 Chronic kidney disease prognosis consortium, Matsushita K, Van der Velde M, Astor BC, Woodward M. Association of estimated glomerular filtration rate and albuminuria with all-cause and cardiovascular mortality in general population cohorts: a collaborative meta-analysis. Lancet 2010;375:2073-81.

4 Foley RN, Parfrey PS, Sarnak MJ. Clinical epidemiology of cardiovascular disease in chronic renal disease. Am J Kidney Dis 1998:32(Suppl 3):S112-9. 
5 Thompson S, James M, Wiebe N, Hemmelgarn B, Manns B. Cause of death in patients with reduced kidney Function. J Am Soc Nephrol 2015;26:2504-11.

6 Gansevoort RT, Correa-Rotter R, Hemmelgarn BR et al. Chronic kidney disease and cardiovascular risk: epidemiology, mechanisms, and prevention. Lancet 2013:382:339-52.

7 Masson P, Webster AC, Hong M et al. Chronic kidney disease and the risk of stroke: a systematic review and meta-analysis. Nephrol Dial Transplant 2015;30:1162-9.

8 NHS Digital. Health survey for England 2016 kidney and liver disease. NHS, 2017. https://files.digital.nhs.uk/publication/m/e/ hse2016-adult-kid-liv.pdf.

9 O'Hare AM, Choi AI, Bertenthal D et al. Age affects outcomes in chronic kidney disease. J Am Soc Nephrol 2007;18:2758-65.

10 Chang AR, Grams ME, Ballew SH, Bilo H, Correa A. Adiposity and risk of decline in glomerular filtration rate: meta-analysis of individual participant data in a global consortium. BMJ 2019;364:k5301.

11 Hsu CY, McCulloch CE, Iribarren C, Darbinian J, Go AS. Body mass index and risk for end-stage renal disease. Ann Intern Med 2006;144:21-8.

12 Navaneethan SD, Yehnert H, Moustarah F et al. Weight loss interventions in chronic kidney disease: a systematic review and metaanalysis. Clin J Am Soc Nephrol 2009;4:1565-74.

13 T Alder AI, Stevens RJ, Manley SE et al. Development and progression of nephropathy in type 2 diabetes: The United Kingdom prospective diabetes study (UKPDS 64). Kid Int 2003;63:225-32.

14 The Renal Association. UK Renal Registry: The seventeenth annual report. Bristol: The Renal Association, 2014. www.renalreg.org/ reports/2014-seventeenth-annual-report

15 Jacobsen $\mathrm{P}$, Rossing $\mathrm{K}$, Tarnow $\mathrm{L}$ et al. Progression of diabetic nephropathy in normotensive type 1 diabetic patients. Kidney Int Supp/ 1999;71:S101-5.

16 Klahr S, Levey AS, Beck G] et al. The effects of dietary protein restriction and blood pressure control on the progression of chronic renal disease. N Engl J Med 1994;330:877-84.

17 Ettehad D, Emdin CA, Kiran A et al. Blood pressure lowering for prevention of cardiovascular disease and death: a systematic review and meta-analysis. Lancet 2016;387:P957-67.
18 Xie X, Atkins E, Lv ] et al. Effects of intensive blood pressure lowering on cardiovascular and renal outcomes: updated systematic review and meta-analysis. Lancet 387:P435-43.

19 Cheung AK, Rahman M, Reboussin DM et al. Effects of intensive BP control in CKD. J Am Soc Nephrol 2017;28:2812-23.

20 The SPRINT Research Group. A randomized trial of intensive versus standard blood-pressure control. N Engl J Med 2015;373:2103-16.

21 Ravera M, Re M, Deferrari L, Vettoretti S, Deferrari G. Importance of blood pressure control in chronic kidney disease. JASN 2006;17(4 suppl 2):S98-103.

22 Jafar TH, Stark PC, Schmid CH et al. Progression of chronic kidney disease: The role of blood pressure control, proteinuria, and angiotensin-converting enzyme inhibition: A patient-level meta-analysis. Ann Intern Med 2003;139:244-52.

23 Lewis JB, Berl T, Bain RP, Rohde RD, Lewis EJ. Effect of intensive blood pressure control on the course of type 1 diabetic nephropathy. Collaborative Study Group. Am J Kidney Dis 1999;34:809-17.

24 Levey AS, Bilous R, Shlipak MG. CKD and diabetes: what can we learn from their similarities and differences? Am J Kidney Disease 2016;67:360-3.

25 Deferrari G, Ravera M, Berruti V. Treatment of diabetic nephropathy in its early stages. Diabetes Metab Res Rev 2003;19:101-14.

26 Baigent C, Landray M], Reith C et al. The effects of lowering LDL cholesterol with simvastatin plus ezetimibe in patients with chronic kidney disease (Study of Heart and Renal Protection): a randomised placebo-controlled trial. Lancet 2011;377:2181-92.

27 Carter BD, Abnet CC, Feskanich D et al. Smoking and mortality beyond established causes. N Engl ] Med 2015;372:631-40.

Address for correspondence: Dr Aruna Arjunan, Dorset County Hospital NHS Foundation Trust, Nephrology, 11 St Martins place, Dorchester, Dorset DT1 2JY, UK.

Email: aruna.arjunan@dchft.nhs.uk 